\title{
Article
}

\section{Study on the impact of lack of fusion in the fillet weld on its fatigue strength under various load combinations}

\author{
Kwiryn Wojsyk ${ }^{1}$, Jerzy Nawrocki ${ }^{1, *}$ \\ ${ }^{1}$ Czestochowa University of Technology; Poland \\ Kwiryn Wojsyk, Ph.D.; kwiryn@gmail.com; \\ * Correspondence: Jerzy Nawrocki, Ph.D.; jureknawrocki@gmail.com
}

Received: 02.10.2019; Accepted: 22.01.2020

\begin{abstract}
The article refers to the issue of incomplete penetration in T-joints allowed by the obligatory Eurocode EN 1993-1-8. Based on it, the joint's model was made, and then they were FEM simulated in various load combinations. As a result of this simulation, a Whöller's graph was obtained. In the experimental part a T-joint was made. A static tensile test was carried out on it, which showed the areas of stress concentration and plasticization anticipated earlier during the simulation. The study concluded that the lack of mutual penetration of fillet welds generates a decreases of fatigue endurance.
\end{abstract}

Keywords: FEM modelling; fillet weld; fatigue load

\section{Introduction}

Designing of welded structures which operate under variable load conditions requires consideration of many factors, the most important of which is determining the structure durability, its sensitive nodes and level as well as the stress gradient occurring in them. Their inclusion leads to the proper shaping of structural elements.

Originally, construction designs were preceded by extensive, usually very expensive and long-lasting experiments. These tests and the results obtained usually led to the determination of unlimited fatigue strength, resulting from the use of a static combination of loads and large or overly estimated safety factors. The effects of such pragmatics were the work of structural elements with a very low load utilization rate or an underestimation of stress concentration and crack initiation in key places of the structure. The use of virtual models of welded structures and simulations using the finite element method (FEM) creates the ability to precisely determine the durability of any structural elements and their joints under real load conditions.

This paper presents a simulation of the consequences of using Eurocode PN-EN 1993-1-8: 2006 (Design of steel structures - Part 1-8: Design of joints) regarding the presence of fillet welds in $\mathrm{T}$ and cruciform joints instead of obtainable natural butt welds. This standard applies to the design of structures operating under static and quasi-static loads, but sensitive construction sites existing in any loadable system can cause a failure or catastrophe of any welded structure.

The article presents a simulation of a T-joint with fillet welds with incomplete penetration made in accordance with Eurocode 1993-1-8, which specifies the rules for calculating the load capacity for nodes of basic steel structures under "predominantly static" loads. Simulations of fatigue parameters were made in the article, for this reason reference was made to Eurocode PN-EN 1993-1-9: 2007 (Design of steel structures - Part 1-9: Fatigue).

A review of the literature did not reveal a publication focusing on the above issue. In terms of analysis, simulation and experiments of T-joints, the focus was more on residual stress, FEM simulation of welding technologies $[1 \div 5]$. A general review of the problem of stress simulation in welded joints is included in the publication [6]. The subject of designing welded joints based on Eurocode was sporadic [7]. An analysis of the load capacity simulation of typical nodes designed on the basis of Eurocode 1993-1-8, but excluding the effect of weld penetration is included in the publication [8].

\section{Description of the joint model}

Dimension of incomplete fusion is shown in Figure 1, the cnom value comes from the Eurocode PN-EN 1993-1-8. In the simulation, a native material model corresponding to the properties of non-alloy steel 
S235JRG2 according to PN-EN 10025-2 (Hot rolled products of structural steels - Part 2: Technical delivery conditions for non-alloy structural steels) and a model of additional material corresponding to solid wire grade G3Si1 for the MAG process according to PN -EN ISO 14341 (Welding consumables - Wire electrodes and weld deposits for gas shielded metal arc welding of non-alloy and fine grain steels). For the purposes of simulation, a T-joint and incomplete mutual penetration of two fillet welds were modeled in accordance with Figure $1 \mathrm{~b}$.

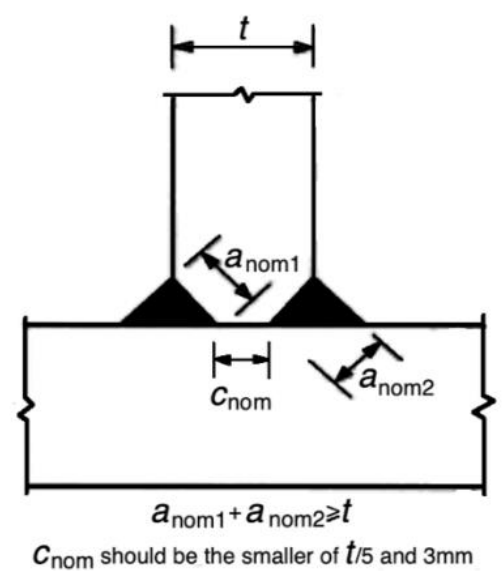

(a)

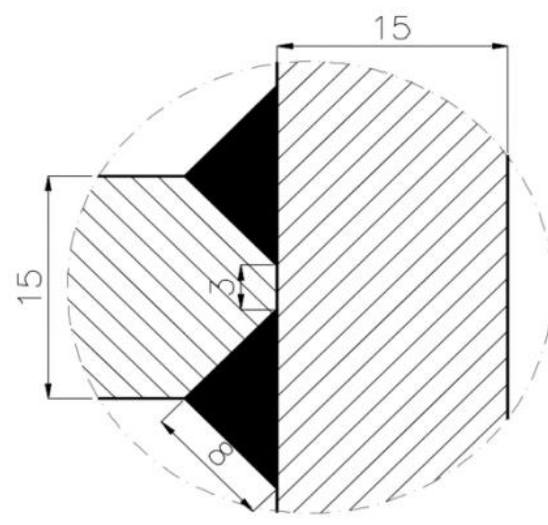

(b)

Fig. 1. Boundary incomplete penetration of fillet welds: a) according to Eurocode, b) dimensions of model used for simulation

For calculations, the division into tetragonal finite elements was used, taking into account the principle of mesh compaction in places of special importance. The degree of compaction was dependent on the distance of the analyzed area, the highest compaction was used between two opposite welds, which was marked in Figure 1a as Cnom. Parameters of the analyzed FEM model:

- size of the smallest finite element $0.1 \mathrm{~mm}$;

- number of nodes 329689 ;

- number of finite elements 233456.

Figure 2 presents models of joints with full penetration, incomplete penetration in accordance with the principles described in Figure 1 and the method of mesh compaction around the expected stress concentration.

The work performed simulations for a range of low-cycle loads and elastic-plastic deformations. As a rule, this type of load causes a full hysteresis loop in each cycle. Examination of changes in material hysteresis fields in laboratory conditions can determine whether variable loads strengthen or weaken a given material. The principle of designing welded joints is to keep stress under normal operating conditions well below the yield point.

The method of fatigue analysis used in the simulation involving the number of deformation cycles to destruction (Strain Life) is experimentally verifiable because it allows you to measure the deformation of sufficiently large elements. Fatigue simulations in the program used in this work use the Ramberg-Osgood equation, which is based on the postulate that total deformation is the sum of elastic and plastic deformations [9]. Fatigue analysis was carried out for the stress ratio $\mathrm{R}=-1$.

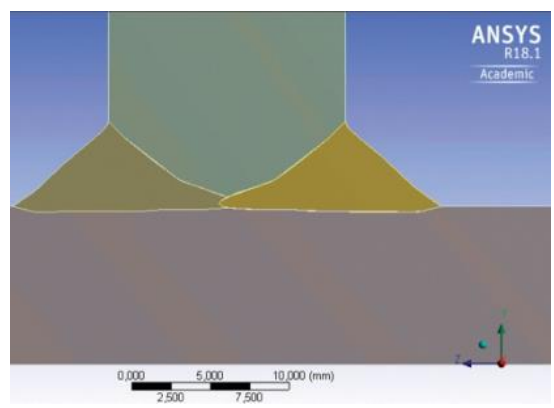

(a)

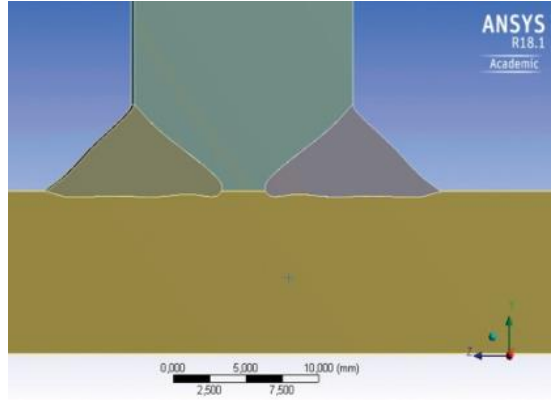

(b)

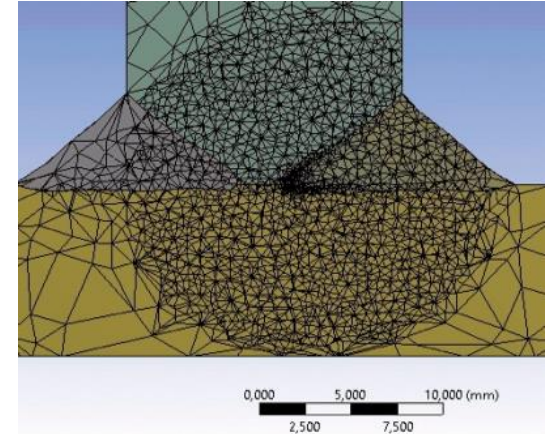

(c)

Fig. 2. Welded joints models: a) with penetration, b) without penetration, c) scheme of mesh compaction 
Figure 3 presents three load variants used in the simulation. They were clean: tensile, bending and torsion. The limit value of Huber-Mises-Hencky's (HMH) reduced stress was set at $70 \%$ of the ReH minimum yield strength. This is due to the fact that in design practice, the reduction factors used during designing the structure reduce the maximum allowable stress to approximately this level.

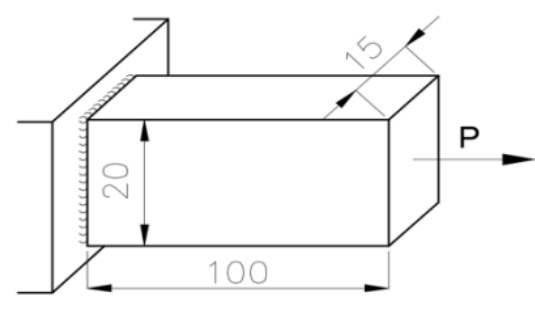

(a)

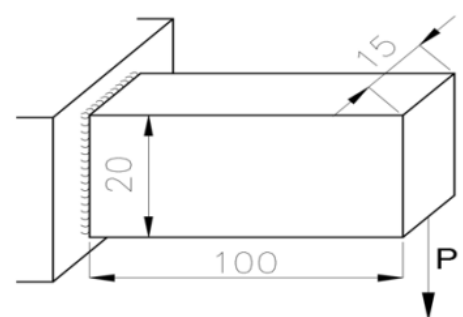

(b)

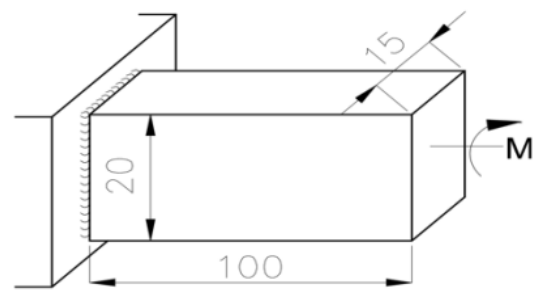

(c)

Fig. 3. Load combinations: a) tensile; b) bending; c) torsion

The criterion used was the definition of the conventional yield strength $\mathrm{R}_{0,05}$, which defines this stress as giving $0.05 \%$ strain. For the analyzed butt joint and native material of S235 steel with typical parameters $(E=210 \mathrm{GPa}, v=0.3)$, the longitudinal elongation $\varepsilon$ for the yield strength is $225 / 210000=0.00107(0.107 \%)$. Therefore, it was assumed that the plasticization of native material will start in a place where the simulation result will indicate elongation values above 0.00107 .

\section{Simulation results}

Figure $4 \mathrm{~b}$ enlarges the location with the lack of penetration. A significant enlargement of this zone made it possible to show the gap between the beam and the plate, which appears when the joint is stretched. In this way, it was confirmed that the contact issues between the elements of the connector were performed correctly. Figure 4a shows the stress distribution of a fully penetrated joint, where for obvious reasons the gap does not occur. From the point of view of static loads, the lack of full penetration of the loaded joint to the value of approx. $50 \% \mathrm{R}_{\mathrm{eH}}$ will not cause plasticization in the fillet weld's root. For tensile with a value of $180 \mathrm{MPa}(80 \% \mathrm{ReH})$, the surface of the plasticized zone measured from the simulation is about $1 \mathrm{~mm}^{2}$. Figure 5 shows simulation results for extreme conditions, i.e. penetrated and non-penetrated joints for three different load combinations. A full penetration reference sample showed a strain life value of 138,000 cycles. For comparison, when stretching with a value of $180 \mathrm{MPa}$, the value of strain life at the place of nonpenetration was only 2140 cycles, for torsion 14900 and for bending 3140 cycles.

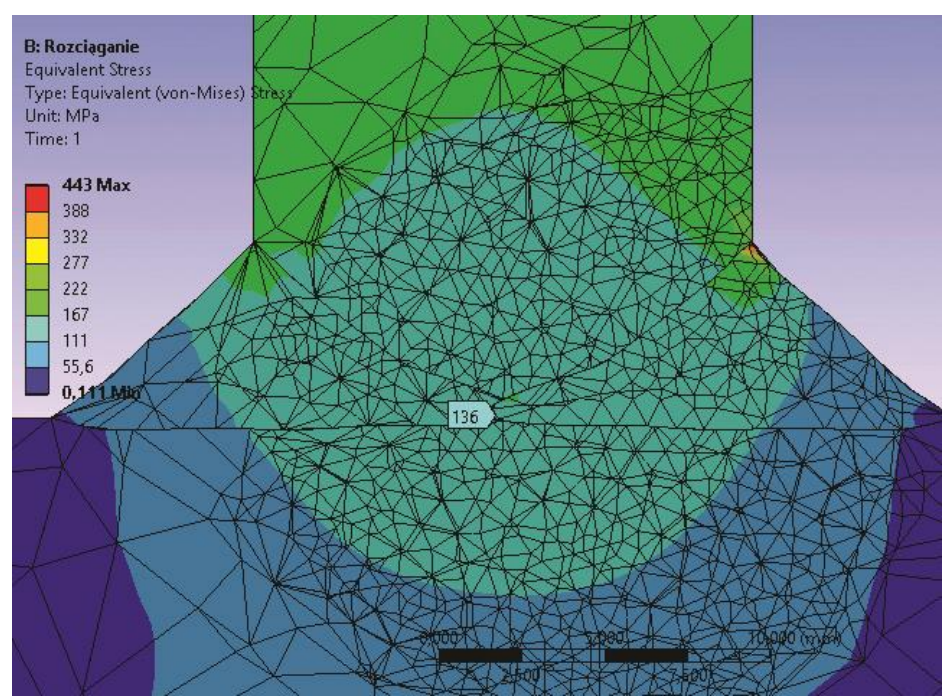

(a)

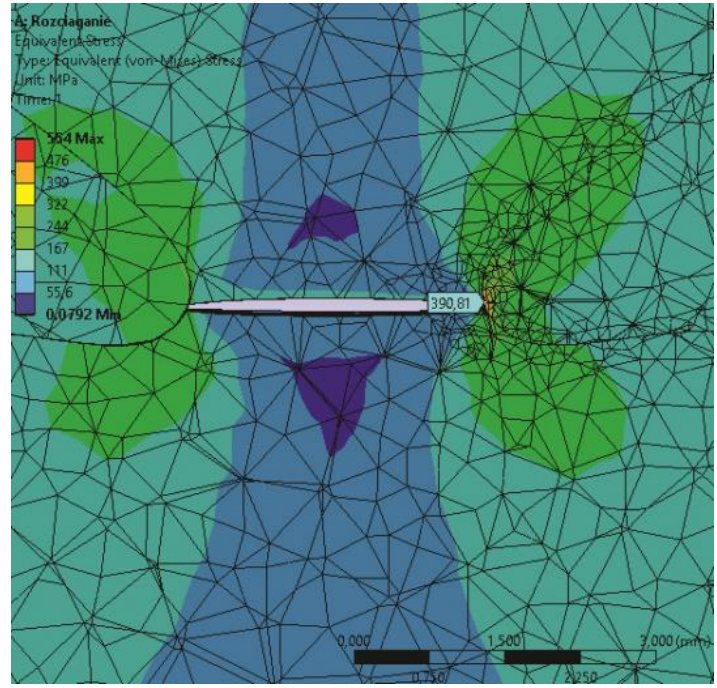

(b)

Fig. 4. Stress field distribution for tensile value of $80 \%$ ReH: a) benchmark sample with full penetration, b) the sample without penetration regards with figure 2 


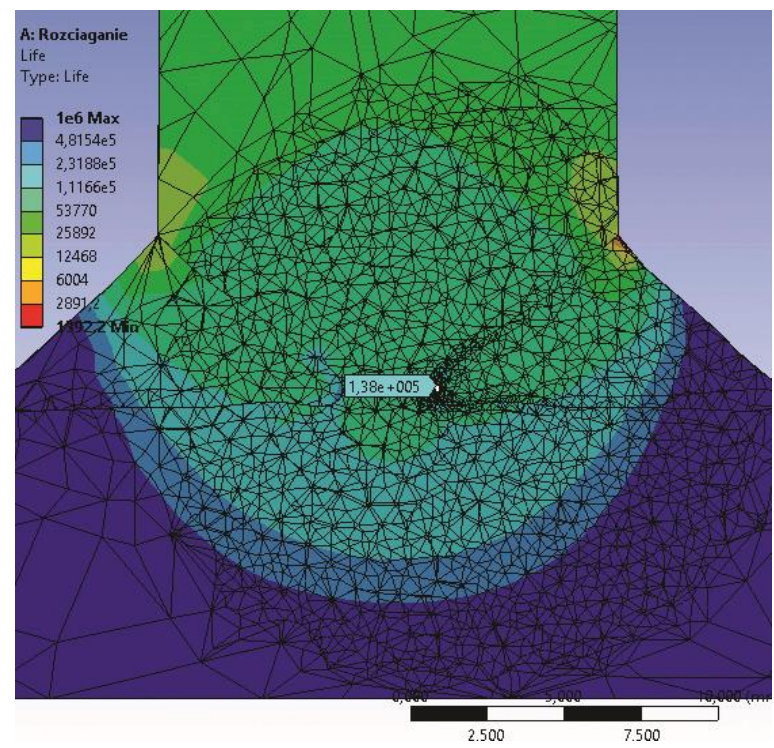

(a)

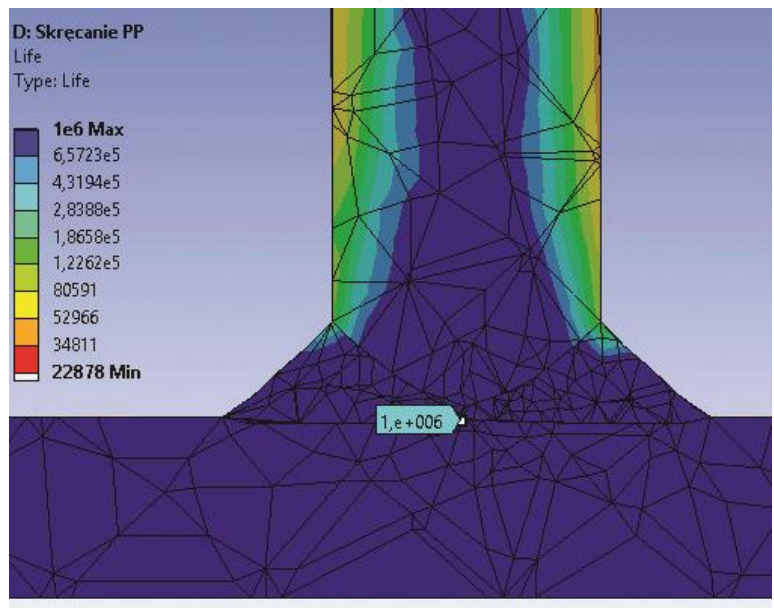

0,000

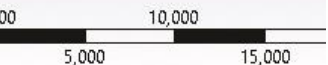

(c)

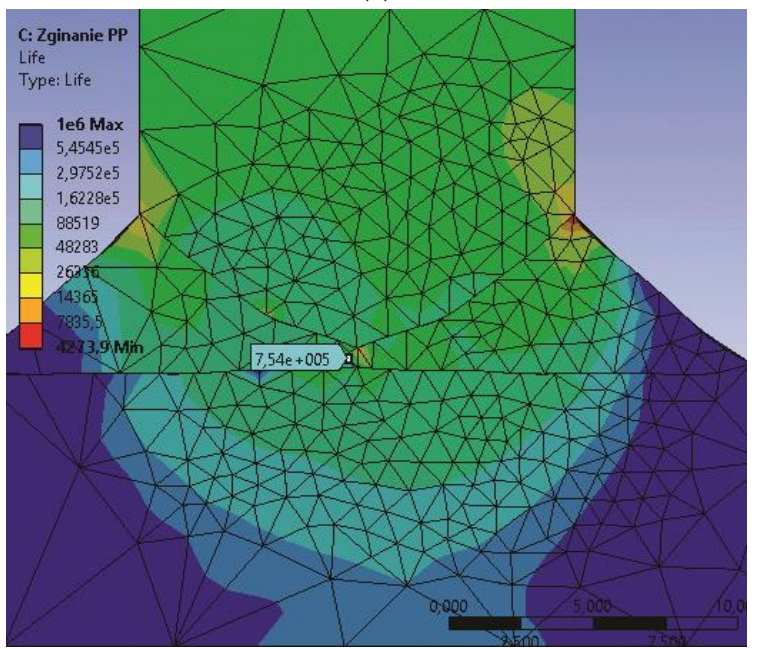

(e)

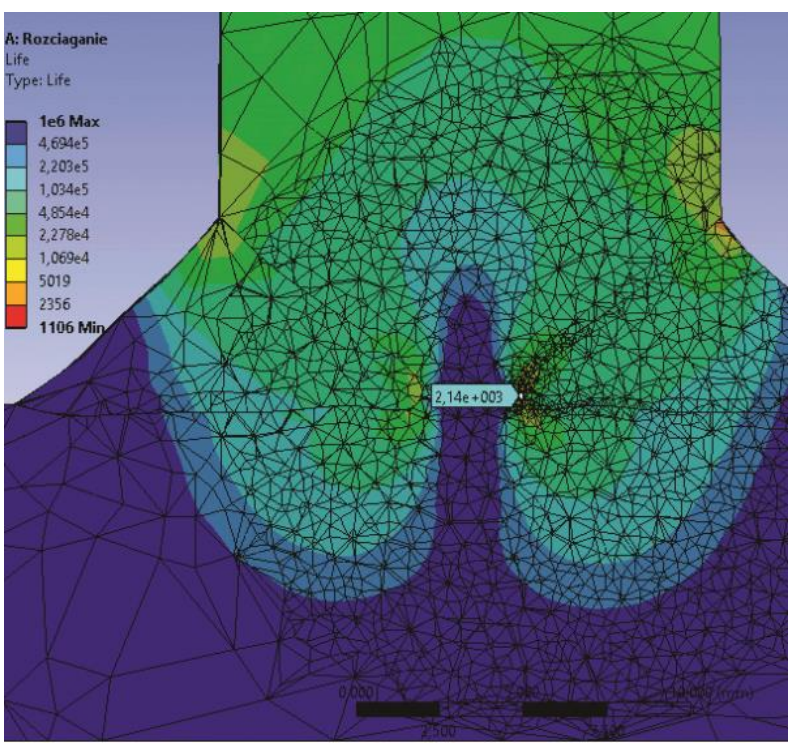

(b)

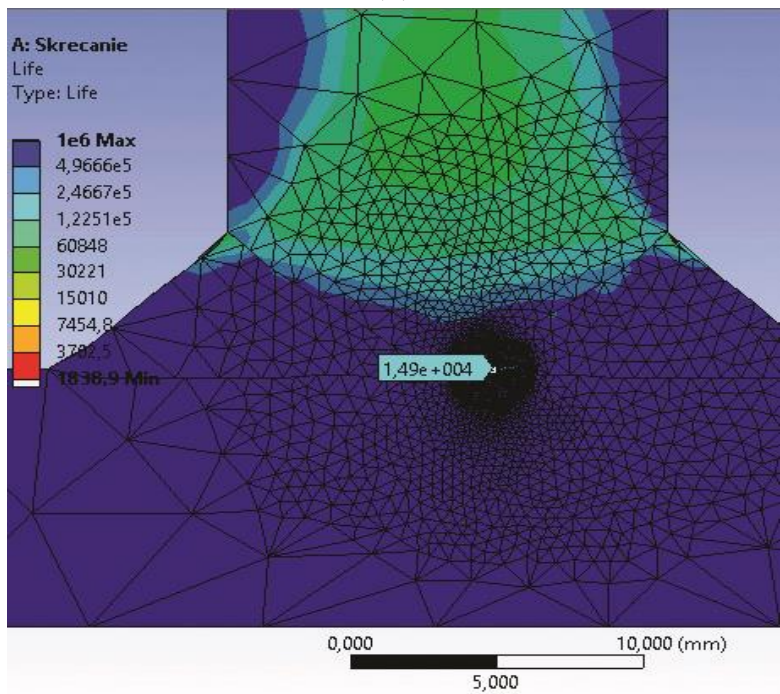

(d)

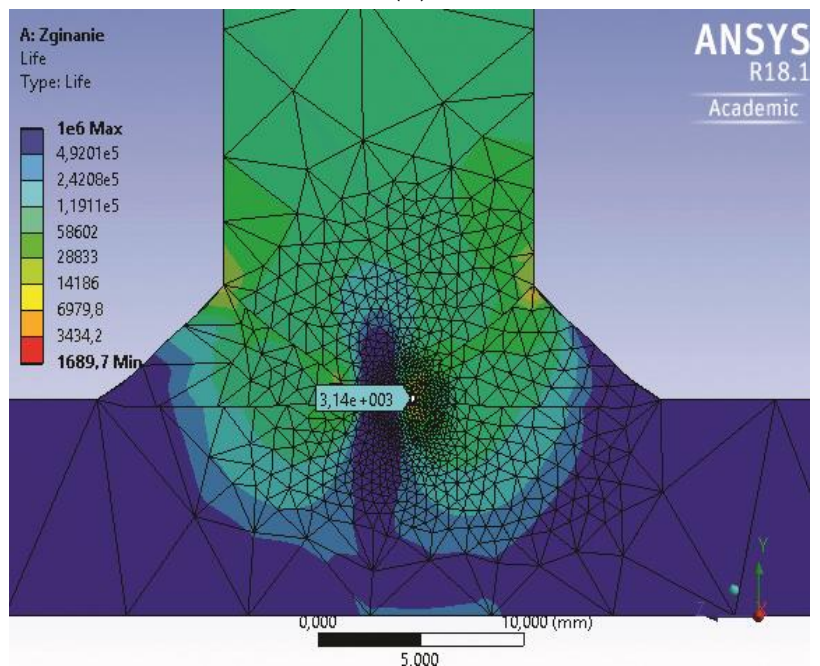

(f)

Fig. 5. Tensile stress distribution with $80 \%$ of yield stress: a) benchmark sample with full of penetration; b) sample without of penetration, according with Fig. 2; c) benchmark sample with full of penetration - torsion; d) benchmark sample without penetration - torsion; e) benchmark sample with full of penetration - bend; f) the sample without penetrasion - bend 
The Strain Life parameter values for individual load combinations are presented in Table I.

Figure 6 presents the traditional Wöhler chart for three load combinations of the weld under analysis without using the modified Wöhler MWCM curve method in this case [10].

Table I. Strain Life values for individual load combinations

\begin{tabular}{cccccccccc}
\hline \% R R & \% & 10 & 20 & 30 & 40 & 50 & 60 & 70 & 80 \\
$\mathbf{R}_{\mathbf{e H}}$ & $\mathrm{MPa}$ & 22 & 45 & 67 & 90 & 113 & 136 & 158 & 180 \\
SLroz & Number of cycles & 1000000 & 1000000 & 133000 & 53400 & 9700 & 2960 & 3440 & 2140 \\
SLsKr & Number of cycles & 1000000 & 1000000 & 264000 & 254000 & 139000 & 46700 & 22100 & 14900 \\
SLzGN & Number of cycles & 1000000 & 458000 & 61100 & 11200 & 10200 & 8720 & 4400 & 3140 \\
\hline
\end{tabular}

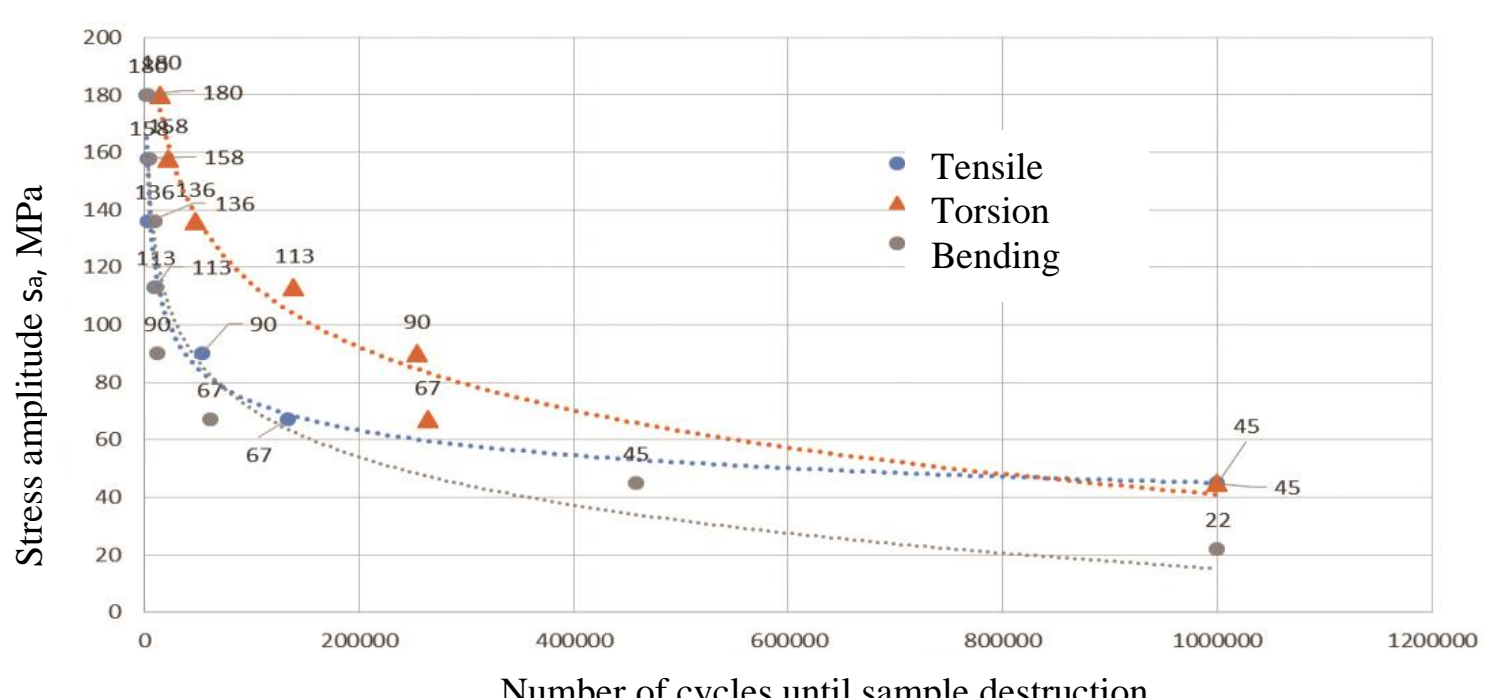

Number of cycles until sample destruction

Fig. 6. Whöler chart for various load combinations

The simulation used the recommendations contained in Eurocode PN-EN 1993-1-8 describing the principles of designing joints in predominantly static conditions, and then the joint was subjected to fatigue loads. Figure 7 shows a fragment of Table 8.5 "Load-carrying welded joints" from Eurocode 1993-1-9. Description of incomplete penetration refers to damage at the edge of the weld but, does not refer to the notch formed in the vicinity of the lack of penetration [11,12]. Eurocode recommends for the cruciform or tee joint the normal stress of the lowest fatigue category, i.e. 36. The numerical value in MPa means the normative fatigue strength for variations of stresses with constant amplitude and durability for $\mathrm{N}=2 \times 10^{6}$ cycles.

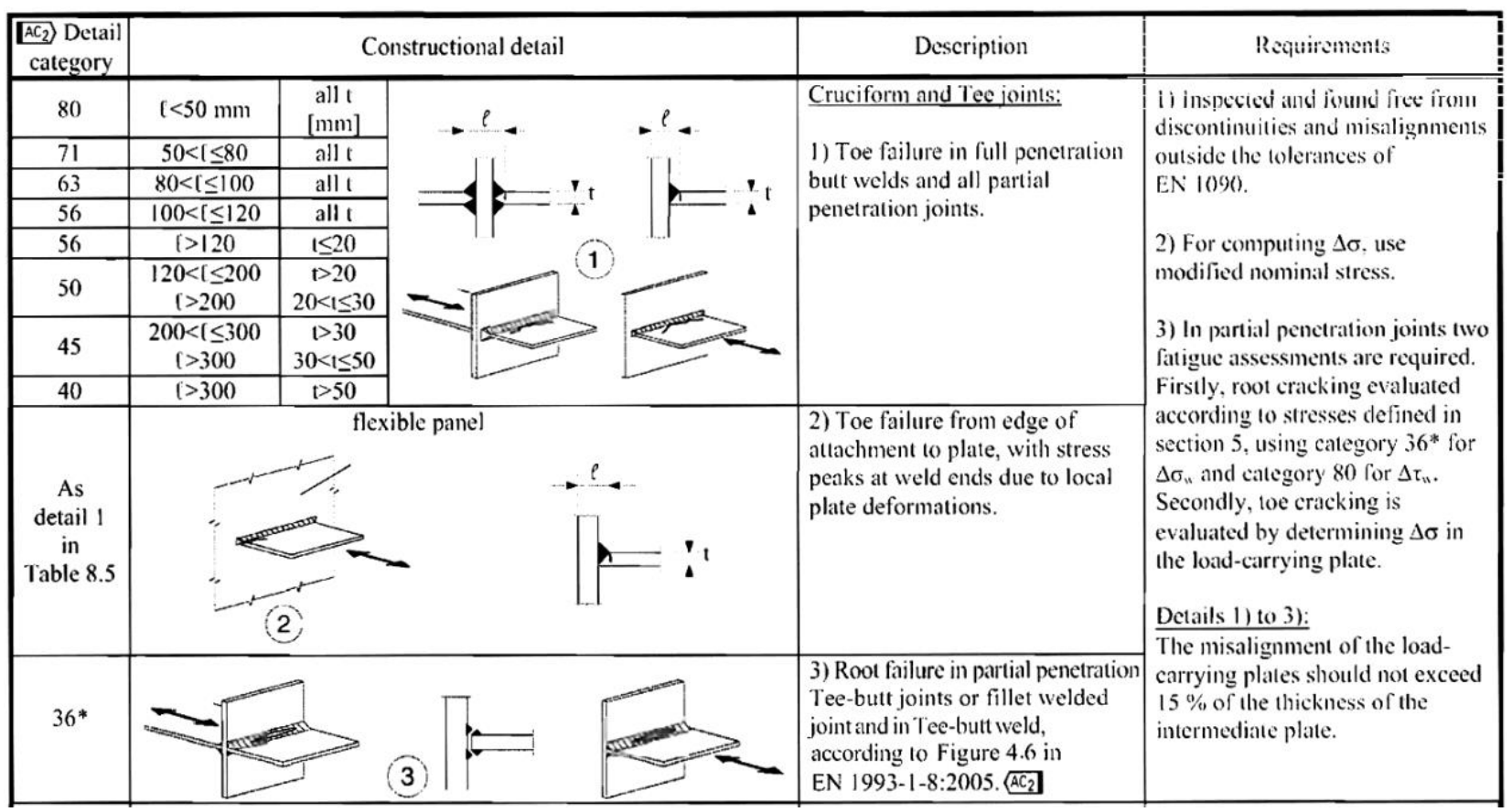

Fig. 7. Part of Tab. 8.5 from Eurocode 1993-1-9 
In the light of the simulations performed, the adoption of such a low fatigue category should be considered justified, but it should be emphasized that the notch description applies to a different place of destruction than in the joint analyzed in this work.

\section{Tee joint stretching results}

Figure 8 shows the results of a T-joint tensile test with fillet welds without mutual penetration. The tensile failure occurred, as was to be expected, in the native material. It is obvious that the tensile test produces such a high level of stress that will never occur under normal joint operation. Despite this, Figures $8 \mathrm{c}$ and $8 \mathrm{~d}$ clearly confirm the results of the simulation and the principle that stress concentration caused by lack of penetration causes crack initiation in the weld root.

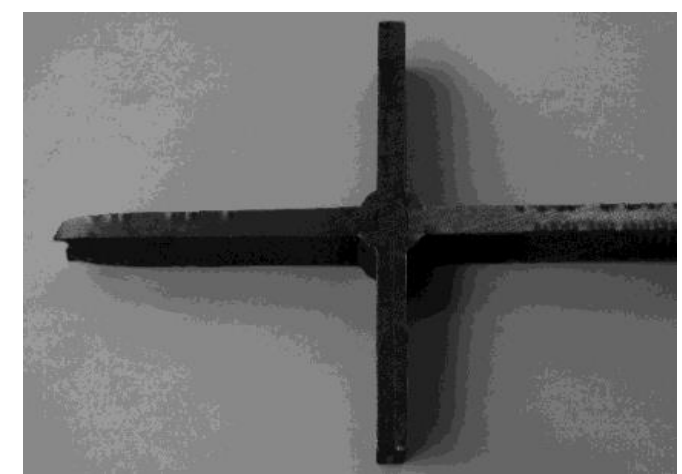

(a)

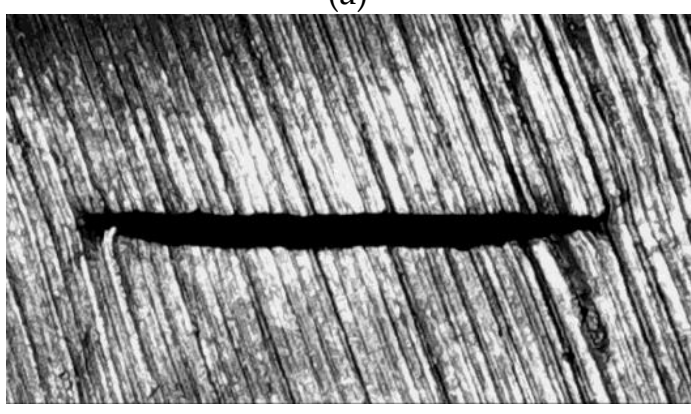

(c)

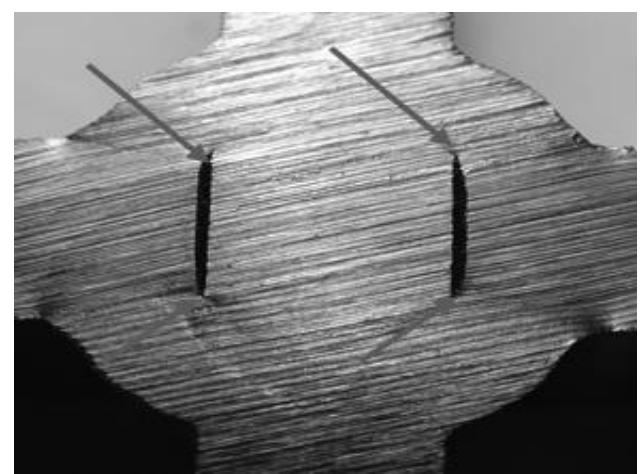

(b)

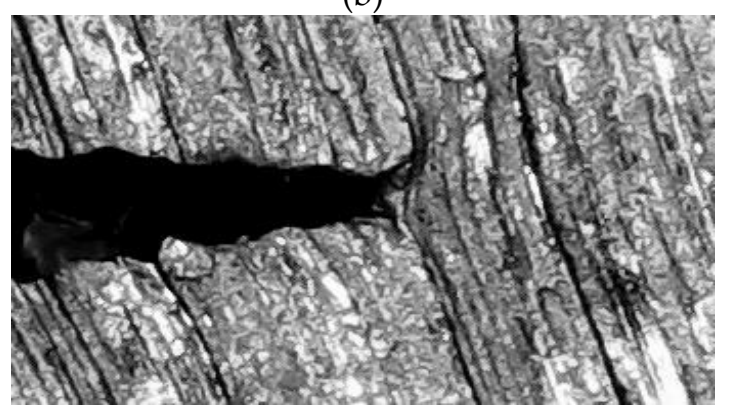

(d)

Fig. 8. T-joint with fillet weld without of penetration: a) general view of the joint, b) joint detail, c) no fusion area, d) yield area in the corner

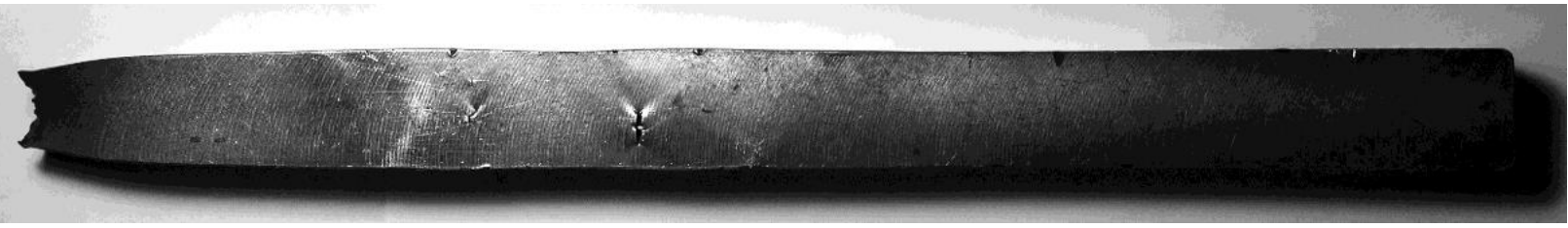

(a)
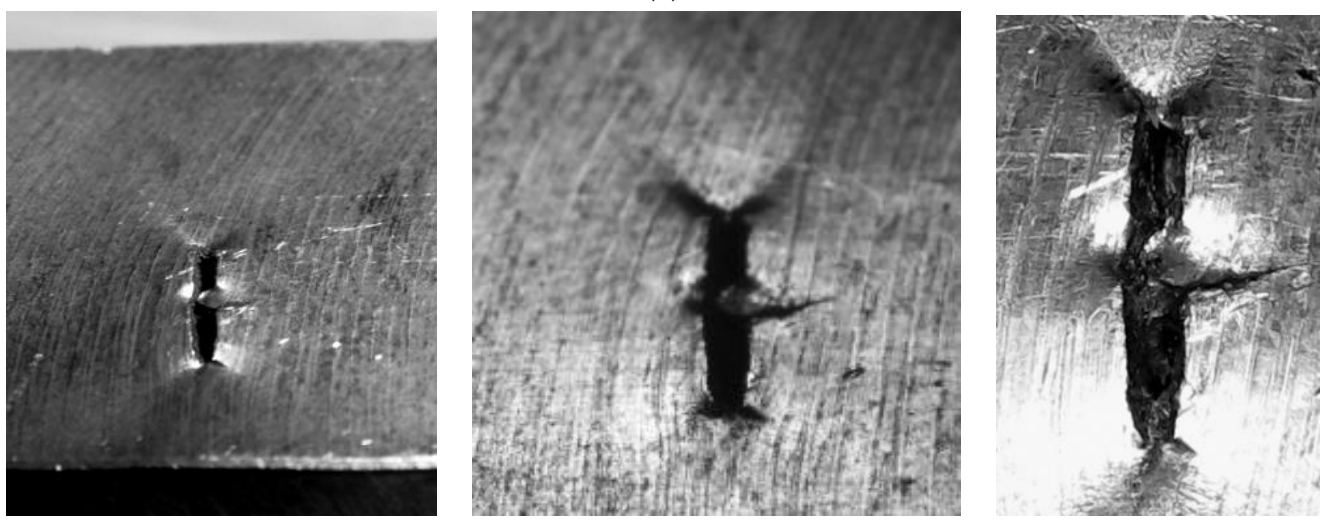

(b)

Fig. 9. T-joint fillet weld without penetration: a) general view of the joint, b) area of stress concentration on the bottom of crack (notch) 
Figure 9 shows a machined cruciform joint consisting of a $25 \mathrm{~mm} \times 25 \mathrm{~mm}$ square rod and T-joints with two welds beveled at K. Figure 9a shows two deficiencies of penetration: larger and smaller on both sides of the cruciform joint. The characteristic shape of the plastic zones at the top of the crack in the form of two petals is perfectly visible. This is the shape of the plastic zones in the joint stretching simulations with no complete penetration.

\section{Conclusions}

1. Lack of mutual penetration of fillet welds generates a significant fatigue notch.

2. The shape of the stress field significantly depends on the load combination used.

3. The presence of notches in the ridge of a T-joint drastically reduces the operational safety of this node, and thus of the entire structure.

4. Plasticization of the ridge and a radical increase in stress in this region begins at a low (50\%) level of applied stress, which is well below that taken for structural calculations.

5. Despite the fact that the considered solution was adopted in the standard for calculating statically and quasi-static loaded constructions, the quoted calculations indicate the risk of its application also in these conditions.

6. In the light of the simulation carried out, it seems reasonable to start the tendency to eliminate fillet welds in favor of the leading ones - in design and implementation. This is especially important in fatigue loaded constructions. The already existing deep-penetration welding technologies allow to obtain joints of this type without special difficulties.

Author Contributions: conceptualization, K.W. and J.N.; methodology, J.N.; software, J.N.; validation, K.W., J.N.; formal analysis, K.W.; investigation, J.N.; resources, J.N.; data curation, K.W.; writing - original draft preparation, J.N.; writing-review and editing, J.N.; visualization, J.N.; supervision, K.W.; project administration, K.W.; funding acquisition, K.W.

Funding: This research received no external funding.

Conflicts of Interest: The authors declare no conflict of interest.

\section{References}

[1] Mikno Z., Bartnik Z., Lange A., Sikorski M., Selected problems FEM modeling of steel sheet projection welding (in polish), Welding Technology Review, 2012, Vol. 84(10), 2012, 78-85.

[2] Kik T., Slováček M., Wyględacz B., Numerical analysis of multipass T-joint welding and post welding heat treatment (in-polish), Welding Technology Review, 2016, Vol. 88(5), 101-106. https://doi.org/10.26628/ps.v88i5.622

[3] Tso-Liang Teng, Chin-Ping Fung, Peng-Hsiang Chang, Wei-Chun Yang, Analysis of residual stresses and distortions in T-joint fillet welds, International Journal of Pressure Vessels and Piping, 2001, Vol. 78(8), 523-538. https://doi.org/10.1016/S0308-0161(01)00074-6

[4] Brennan F.P., Peleties P., Hellier A.K., Predicting weld toe stress concentration factors for $\mathrm{T}$ and skewed T-joint plate connections, International Journal of Fatigue, 2000, Vol. 22(7), 573-584. https://doi.org/10.1016/S01421123(00)00031-1

[5] Perić M., Tonković Z., Rodić A., Surjak M., Garašić I., Boras I., Švaić S., Numerical analysis and experimental investigation of welding residual stresses and distortions in a T-joint fillet weld, Materials \& Design, 2014, Vol. 53, 1052-1063. https://doi.org/10.1016/j.matdes.2013.08.011

[6] Nawrocki J., Słania J., Simulation of the stress field in the welded joint using FEM, Welding Technology Review, 2018, Vol. 90(8), 62-67. https://doi.org/10.26628/ps.v90i8.926

[7] Bijlaard F., Eurocode 3, a basis for further development in joint design, Journal of Constructional Steel Research, 2006, Vol. 62(11), 1060-1067. https://doi.org/10.1016/j.jcsr.2006.06.012

[8] Jurč́ková A., Rosmanit M., FEM Model of Joint Consisting RHS and HEA Profiles, Procedia Engineering, 2012, Vol. 40, 183-188. https://doi.org/10.1016/i.proeng.2012.07.077

[9] Draper J., Modern Metal Fatigue Analysis, EMAS Warrington, England, 2008, 154-196.

[10] Susmel L., Modified Wöhler curve method, theory of critical distances and Eurocode 3: A novel engineering procedure to predict the lifetime of steel welded joints subjected to both uniaxial and multiaxial fatigue loading, I International Journal of Fatigue, 2008, Vol. 30(5), 888-907. https://doi.org/10.1016/j.ijfatigue.2007.06.005

[11] Sonawane R.B., Mankar R.L., Hredeya M. Introduction to finite element analysis of fillet welded joints, International Journal for Research in Applied Science \& Engineering Technology, 2017, Vol. 5(12), 363-366. 
[12] Teng T.L., Fung C.P, Chang P.H., Yang W.C., Analysis of residual stresses and distorsions in T-joint fillet welds, International Journal of Pressure Vessels and Piping, 2001, Vol. 78(8), 523-538. https://doi.org/10.1016/S03080161(01)00074-6

[13] Wojsyk K., Kudła K, Consequences of stiffening of welded structures subjected to fatigue load and ways of eliminating negative operational effects (in polish), XXV National Scientific Welding Conference, Poland, Międzyzdroje 2019.

(C) 2020 by the authors. Submitted for possible open access publication under the terms and conditions of the Creative Commons Attribution (CC BY) license (http://creativecommons.org/licenses/by/4.0/). 